

SEÇÃO: ARTIGOS

\title{
A política brasileira sobre drogas e a rede de atenção psicossocial
}

\author{
The Brazilian drug policy and the psychosocial attention network
}

\section{Leonia Capaverde \\ Bulla ${ }^{1}$ \\ orcid.org/0000-0002-7517-3008 \\ leonia.bulla@ufrgs.br}

\section{Camila Bassôa dos \\ Santos $^{2}$}

orcid.org/0000-0003-1658-1869

camilabassoa@gmail.com

Recebido em: 27 maio 2021. Aprovado em: 21 jun. 2021.

Publicado em: 03 set. 2021.
Resumo: No Brasil, a temática das drogas tem sido abordada por diferentes tendências teóricas, em especial, pelo prisma da saúde pública em oposição ao proibicionismo. Tais tendências perpassam a construção da política nacional dessa área no contexto brasileiro, o qual tem sofrido com o desmonte das políticas sociais e a mercantilização da saúde. O presente artigo versa sobre uma pesquisa, na qual foram realizadas entrevistas com usuários de drogas, familiares, profissionais e gestores, nos diferentes niveis da rede de atenção psicossocial. Tal estudo permitiu discorrer sobre os avanços e entraves da efetivação das políticas na área além de evidenciar a importância da integralidade na oferta e acesso às políticas, bem como a intersetorialidade como pilar para atingir a atenção integral aos usuários de drogas. Reforça, também, a importância da luta popular por uma politica fundamentada nos direitos humanos e que compreenda o uso de drogas em sua complexidade.

Palavras-chave: Drogas. Políticas Públicas. Saúde. Rede de Atenção. Intersetorialidade.

Abstract: In Brazil, the theme of drugs has been approached by different theoretical trends, in particular, from the perspective of public health as opposed to prohibitionism. Such trends permeate the construction of national policy in this area in the Brazilian context, which has suffered from the dismantling of social policies and the commodification of health. This article is about a research in which interviews were conducted with drug users, family members, professionals and managers, at different levels of the psychosocial care network. This study allowed to discuss the advances and obstacles to the implementation of policies in the area, in addition to highlighting the importance of integrality in the offer and access to policies, as well as intersectoriality as a pillar to achieve comprehensive care for drug users. It also reinforces the importance of the popular struggle for a policy based on human rights and that understands the use of drugs in their complexity.

Keywords: Drugs. Public Policies. Health. Attention Network. Intersectoriality.

\section{Introdução}

O contexto da pandemia de COVID-19 tem, naturalmente, monopolizado os debates e atenções da sociedade e da comunidade acadêmica, acerca de diversos aspectos relacionados à saúde e em particular à saúde mental. É importante, entretanto, retomar a discussão sobre a política de drogas, porque a pandemia atingiu a toda a sociedade, mas seus impactos foram mais perversos na vida das populações mais vulneráveis, em que se incluem os usuários de substâncias psicoativas. 
Inicialmente, é relevante assinalar-se que o uso de drogas é considerado um fenômeno mundial, que tem tomado grande espaço nas agendas governamentais. Muitas polêmicas são registradas em torno da legalidade e ilegalidade do uso de determinadas substâncias, perpassando crenças e valores subjetivos das pessoas e sociedades. A grande quantidade de informações disponiveis a respeito do tema permite que o fenômeno seja abordado com o devido aporte da investigação acadêmica, proporcionando o repensar de práticas institucionais, profissionais e sociais ao tratar sobre a questão da droga. Ainda atravessado por ideologias, preconceitos e tabus, o fenômeno da compra, venda, consumo e ou dependência das drogas emerge, entretanto, em diversos espaços sócio-ocupacionais, constituindo-se um desafio cotidiano aos profissionais, tanto no âmbito da violência perpetrada pelo tráfico de drogas, quanto pela tensão entre as perspectivas de saúde pública e a lógica proibibicionista. Essa lógica está associada à "guerra às drogas", uma das estratégias mais expressivas e inspiradoras da construção de políticas de enfrentamento às drogas em diversos países.

As substâncias consideradas ilícitas tornaram-se o maior alvo no sentido da repressão, criminalização do consumo, produção e comercialização. Os impactos da lógica proibicionista foram devastadores no âmbito do fortalecimento do tráfico de drogas e no aumento do encarceramento decorrente dessa conduta ilícita. Além disso, diversos usuários foram privados de sua liberdade pelo uso, quando envolvidos com tráfico, e também quando buscavam tratamento de longo prazo em comunidades e ou residenciais terapêuticos. Essas instituições de longa permanência atuaram por muito tempo sem a devida fiscalização dos órgãos da área de saúde, que seria a área competente para tal, provocando o afastamento de usuários de seu convívio familiar, tornando frágeis seus vínculos e cada vez mais difícil seu processo de retorno ao meio social após o tratamento.

Inspirados no movimento da Reforma Psiquiátrica e na luta antimanicomial, houve importantes avanços na legislação brasileira que orientaram a construção de estratégias voltadas para a atenção ao sofrimento psíquico, incluindo o uso prejudicial de drogas, a partir de uma rede de caráter psicossocial, pautada na intersetorialidade, interdisciplinaridade e na atenção integral a essa população no âmbito da saúde mental. Na década de 2010, a redução de danos passou a ser pressuposto básico da política sobre drogas, possibilitando o reconhecimento do usuário como protagonista no seu tratamento, desenvolvendo junto a ele o plano singular terapêutico de acordo com suas necessidades e possibilidades.

A partir das mudanças ocorridas recentemente no país, no âmbito político, foi possivel constatar-se significativos retrocessos na área da saúde mental, que comprometem o âmbito ético e os direitos essenciais da população. Este artigo aborda a construção da rede e aponta os desafios a serem enfrentados pelos que defendem os direitos dos sujeitos que desenvolvem o uso prejudicial de drogas. Compreende-se que assistentes sociais são profissionais que se deparam com demandas advindas da questão das drogas, pertencentes a essa rede e aliados, por seu projeto ético e político, à luta pela garantia de acesso aos direitos da população, contra o desmonte que tem ameaçado as políticas públicas nessa área.

Nesse sentido, o estudo que fundamenta o presente artigo teve como objetivo analisar as políticas e práticas de atenção aos usuários de drogas e seus familiares. A pesquisa realizou-se no Rio Grande do Sul ${ }^{3}$ e buscava contribuir para a qualificação das políticas públicas na área das dro-

\footnotetext{
3 Trata-se da pesquisa "Políticas e práticas de enfrentamento à drogadição no Rio Grande do Sul", vinculada a uma rede internacional de estudos sobre drogas, coordenada pela Federação Internacional de Universidades Católicas (FIUC) e composta pelas seguintes instituições: Universidad de San Buenaventura (Cartagena/Colômbia); Intercâmbios (Buenos Aires/Argentina); Universidad Católica Boliviana San Pablo (La Paz/Bolivia); Universidade Santa Úrsula (Rio de Janeiro/Brasil); Pontifícia Universidade Católica do Rio Grande do Sul (Porto Alegre/Brasil); Assumption University (Tailândia); Atma Jaya Catholic University (Indonésia); Santo Tomás University (Filipinas); Stella Maris College (Índia) e Université Saint - Joseph (Libano). O projeto de pesquisa foi submetido e aprovado pelo Comitê de Ética em Pesquisa da PUCRS e da Plataforma Brasil, tendo sido aprovado. No seu processo de desenvolvimento o projeto recebeu apoios financeiros da FIUC e do CNPQ.
} 
gas, ao aproximar-se dos sujeitos que vivenciam a presença desse fenômeno em seu cotidiano, buscando analisá-lo com aporte científico A fim de compreender os avanços e entraves da efetivação das políticas nessa área, foram ouvidos usuários de drogas, seus familiares, trabalhadores e gestores dos serviços, nos diferentes niveis de atenção em saúde, voltados aos usuários de drogas.

\section{A perspectiva do estudo sobre as drogas}

Para aprofundar a questão das drogas, foi adotada no estudo uma forma mais qualitativa de estudo do fenômeno. Assim, um dos eixos da investigação foi a aproximação com usuários de drogas e suas vivências em relação aos padrões de consumo de drogas, as repercussões em seu cotidiano e os significados que esse fenômeno teve em suas vidas e a relevância ainda atribuida aos mesmos. Dessa forma, o estudo caracterizou-se como uma pesquisa de natureza qualitativa, pois, buscou conhecer trajetórias de vida e experiências sociais dos sujeitos, pressupondo disponibilidade e interesses reais de parte do pesquisado em vivenciar a experiência de participar da investigação (MARTINELLI, 1994).

A pesquisa e o presente trabalho são alicerçados transversalmente na Teoria Social Critica de Marx e embasa-se no Método Dialético-Crítico de leitura da realidade. Foram elencadas como principais categorias a historicidade, a totalidade e a contradição, pois "a dialética é o pensamento crítico que se propõe a compreender a 'coisa em si' e sistematicamente se pergunta como é possivel chegar à compreensão da realidade" (KOSIK, 2002, p. 20).

Orientado por essa perspectiva, o estudo deu prioridade à apreensão do real de forma global, em direção ao desvendamento do fenômeno social, a partir de uma análise que parte da estrutura e busca na história sua gênese, perpassando a articulação dos diversos fatores sociais, políticos, econômicos e culturais que compõem qualquer fenômeno social, além da mediação entre contextos amplos e situações singulares que conformam a categoria da totalidade. $\mathrm{Na}$ perspectiva dialética, a totalidade é um todo articulado, interconectado, mais do que uma reunião de partes, explica Kosik (1976). Levaram-se em consideração, também, as diversas mudanças estruturais e conjunturais e seus impactos na vida comunitária, no cotidiano das pessoas, em suas convivências familiares e que tornam essas pessoas mais vulneráveis.

A totalidade, porém, não é a única categoria imprescindivel à interpretação do real. A partir dessa perspectiva epistemológica, a historicidade que reconhece o movimento e a provisoriedade dos fenômenos é outro elemento de análise e intervenção fundamental. Este processo de reconstituição histórica é necessário para que se possam desvendar as expressões da questão social materializadas na vida de sujeitos, grupos, instituições ou sociedades. Segundo Lefebvre (1991) esse processo se efetiva a partir de um movimento regressivo (que vai ao passado) e progressivo (que retorna ao presente) desvendando as contradições desse percurso para, a partir da reflexão dialética (não só a crítica, mas a articulação de novas mediações) superar suas limitações. Destacam-se, dessa forma, as categorias da totalidade, historicidade e contradição que, de modo historicizado e articulado, orientaram a busca pelo conhecimento.

Quanto aos aspectos metodológicos, é importante que se esclareça que, embora tenha sido dada ênfase especial aos procedimentos qualitativos na pesquisa, foram utilizados, também, instrumentos e técnicas de pesquisa quantitativa, pois, os dados quantitativos e qualitativos tornam-se complementares, quando se considera o mundo dos significados e das relações humanas. Os procedimentos quantitativos tornam possivel a compreensão da abrangência do fenômeno, com a aplicação de técnicas de coleta, tratamento e análise de dados pertencentes ao domínio de valores e quantidades numéricas, podendo-se fazer uso de medidas e procedimentos estatísticos. A pesquisa qualitativa, no entanto, utiliza instrumentos e técnicas qualitativas que permitem o desvendamento de aspectos da realidade que não podem ser quantificados, pois se referem aos significados que as pessoas atribuem aos fenômenos, motivos, aspirações, crenças, valores 
e atitudes. (BAUER; GASKELL, 2002; BOGDAN, 1994; MARTINELLI, 1994).

Em uma primeira etapa do processo de pesquisa, foram realizadas diversas atividades com o objetivo de aprofundar o fundamento teórico inicial da pesquisa, que qualificaram esse referencial. Foram, então, coletados e analisados, documentos acadêmicos (dissertações de mestrado e teses de doutorado em bancos de dados da CAPES e da PUCRS), bem como artigos científicos sobre a temática das drogas nos portais Scielo, Bireme e Lilacs, que contribuiram para a construção do marco teórico conceitual do projeto. Foram aprofundados, dessa forma, vários conceitos teóricos, fazendo-se uso da riqueza da produção científica desenvolvida nos últimos anos, considerando-se ser escassa a produção científica que aborda o nivel de efetividade, as fragilidades e as potencialidades, da rede de atenção aos dependentes de substâncias psicoativas.

A seguir, foi realizado o levantamento da legislação brasileira direcionada ao fenômeno da droga, com o principal objetivo de identificar as concepções e os fundamentos que norteiam as políticas e práticas da rede de serviços em nivel nacional e estadual (RS) nas áreas da saúde, assistência social, justiça e segurança pública. Buscou-se conhecer como a legislação brasileira regula as propostas para as políticas públicas de prevenção, tratamento e reinserção dos usuários de drogas, além das políticas de repressão à produção e comércio de substâncias ilegais, a fim de apreender quais as concepções e os fundamentos que orientam o desenvolvimento dessas ações.

Em preparação ao trabalho de campo, foram mapeadas as instituições e organizações que seriam abordadas na pesquisa, através do seu cadastro no Observatório Brasileiro de Informações sobre Drogas (OBID), conforme seu eixo de atuação. A partir desse mapeamento, foram identificados e classificados os programas e serviços de atenção aos usuários de drogas existentes no estado do Rio Grande do Sul e, através do geoprocessamento dos dados, foram construidos mapas ilustrativos da distribuição e localização das instituições. Para seleção e dis- tribuição da amostra da pesquisa, o estado do Rio Grande do Sul foi dividido em nove regiões funcionais, utilizando-se os critérios da Secretaria de Planejamento, Gestão e Participação Cidadã do Rio Grande do Sul (SEPLAG).

A coleta de dados abrangeu 66 instituições, em que foram entrevistados 241 sujeitos: 92 usuários de drogas, 37 familiares de usuários, 59 gestores e 53 trabalhadores/ profissionais. As entrevistas dos usuários compõem a maior parte da amostra, pois a fala dos mesmos foi priorizada na metodologia da presente pesquisa, em que dois usuários de cada instituição eram contatados, diferentemente de apenas um representante dos demais sujeitos. Os dados coletados foram analisados segundo os objetivos específicos previstos no estudo, com o real intuito de aportar contribuições à qualificação dos serviços de atenção aos usuários de drogas e seus familiares. Posteriormente, foi possivel relacionar a revisão teórica com os dados coletados, frutos da pesquisa de campo, realizando-se sucessivas aproximações ao objeto pesquisado (KOSIK, 2002).

\section{As polêmicas sobre as drogas no contexto brasileiro}

As drogas estão presentes na sociedade como um fenômeno atravessado por ideologias, preconceitos e tabus, devido às diferentes formas de interação que os seres humanos desenvolveram ao longo do tempo com essas substâncias. É tema emergente em diversos espaços sócio-ocupacionais, tornando-se desafio cotidiano dos profissionais atenderem às demandas que advém dos diferentes impactos das drogas na vida dos sujeitos. Além disso, existem tensões que perpassam as distintas perspectivas que norteiam as ações direcionadas a essa questão, tais como as antagonistas perspectivas: a proibicionista que coloca o foco somente na abstinência e na repressão - e a questão das drogas no âmbito da saúde pública, que adota as estratégias de redução de danos, entre outros enfoques.

O proibicionismo e o antiproibicionismo perpassam os setores que correspondem à justiça e à segurança pública. O proibicionismo está ligado 
à perspectiva da chamada "guerra às drogas", focando-se principalmente no combate ao tráfico e na criminalização de usuários e traficantes, tendo como "horizonte" uma sociedade sem a presença das drogas. Aliado a esse posicionamento, foram desenvolvidos diversos acordos e tratados internacionais "antidrogas", os quais influenciaram a construção de políticas, inclusive no âmbito da América Latina, posicionando-se em direção ao compromisso de erradicar o uso, prevenir o consumo e repreender a produção e a oferta de drogas. No antiproibicionismo, paradigma em disputa com o proibicionismo, a principal defesa se dá pela descriminalização e a legalização das drogas, ao reconhecer que seu uso prejudicial deve ser tratado e cuidado pelo setor da saúde, não o considerando como crime e não devendo envolver reclusão dos sujeitos em ambientes prisionais (TEIXEIRA; RAMOA; ENGSTROM; RIBEIRO, 2017).

Ainda na área da saúde, associada à assistência social ocorre a disputa entre as propostas asilar, psicossocial e a redução de danos. A abordagem asilar caracteriza-se pela utilização de medicamentos como ferramenta primordial no tratamento, e nele o sujeito assume posição "passiva", sendo isolado do convívio social e do meio familiar por um determinado tempo. As instituições representativas desse modelo de tratamento são os hospitais psiquiátricos e as comunidades terapêuticas, que possuem internações de longa permanência.

O modelo "psicossocial" aparece, na área da saúde, como promotor de práticas que derivam dos movimentos sociais e de diferentes campos teóricos, os quais compreendem o sofrimento psíquico e o uso prejudicial de drogas para além da dependência química. Dessa forma, este modelo visa ultrapassar o exclusivo trato medicamentoso, a fim de contextualizar o fenômeno do uso de drogas conforme os determinantes econômicos, sociais e políticos que nele estão implicados. A partir disso, o cuidado se dá nas redes de atenção, que atuam de forma territorializada, orientadas pelos princípios da integralidade na atenção ao sujeito. O objetivo principal do tratamento na rede não visa a necessidade da abstinência, direcionando-se à redução de riscos e danos à vida do sujeito. Outros princípios que norteiam esse modelo são a desinstitucionalização, a autonomia dos sujeitos frente a seus tratamentos, a interdisciplinaridade e a intersetorialidade. (TEIXEIRA; RAMOA; ENGSTROM; RIBEIRO, 2017).

As disputas presentes nos campos da segurança, justiça, saúde e assistência social estão refletidas em diferentes modelos e abordagens para a atenção aos sujeitos que fazem uso de drogas. A ilicitude de algumas substâncias torna seu uso, produção e distribuição passivel de penalidades legais, como o modelo moral/criminal. As políticas fundamentadas no proibicionismo visam a redução da oferta, além de se orientarem pelo ideal moral, o qual sugere que o sujeito que desenvolve uso prejudicial ou dependência de drogas não está sob posse de sua capacidade de discernimento quanto ao que é "certo" e "errado", sendo passivel de ser submetido a medidas de suspensão de seus direitos individuais.

Pode-se observar que a forte conotação moral dificulta abordagens que incluam maior aproximação aos usuários. Há uma associação equivocada, por parte da sociedade e inclusive de muitos profissionais que atuam na atenção aos usuários de drogas, de que o usuário seja "fraco", "sem força de vontade", "mau caráter" ou que o uso e a dependência são "problemas sem solução" (ANDRADE; RONZANI, 2017, p. 33). Dessa forma, acabam reforçando as práticas que, ao unir justiça e saúde, sugerem as internações compulsórias, determinadas por juizes, direcionadas à abstinência total (MARLATT, 1999).

O debate sobre a via da internação prolongada para tratar o uso prejudicial de drogas é latente na sociedade. Muitas campanhas e reportagens foram veiculadas na mídia mostrando usuários de crack como pessoas sem autodeterminação, em alguns momentos até retratados como "zumbis", reforçando a ideia de que, após o primeiro contato com a droga e, de forma imediata, a pessoa se tornaria dependente. A mídia, ao explorar aspectos degradantes das trajetórias de usuários de drogas, relacionou a degeneração 
do caráter e do comportamento das pessoas ao uso prejudicial, o que as impediria de exercer sua autonomia frente a decisões acerca das alternativas de tratamento. Dessa forma, o Estado estaria autorizado a decidir por seu tratamento e/ou abrigamento compulsórios, medidas que são violadoras dos direitos humanos.

Foram crescendo, dessa forma, projetos voltados à internação compulsória, como estratégia mais eficaz para os usuários, ou seja, uma medida de recolhimento, com o uso da força, para encaminhá-los ao tratamento. É falacioso fazer crer que a internação compulsória, por si só, iria tratar da forma correta essas pessoas, tendo em vista que o uso prejudicial de drogas, dada a sua complexidade, necessitaria de articulação intersetorial de políticas públicas e sociais para, dessa forma, oferecer atenção integral necessária ao sujeito que dela necessitar.

O modelo vinculado à internação compulsória, como via de tratamento, desconsidera todas as determinações históricas e sociais que envolvem o modo como os sujeitos se relacionam com a droga, bem como o contexto sociocultural do uso. Trata-se de um fenômeno complexo, histórico, multideterminado e necessita de respostas das várias políticas sociais, não de modelos baseados em isolamento e encarceramento da população usuária. A internação compulsória aparece, também, como impulsionadora de interesses econômicos e políticos do capital, a qual, a partir da lógica higienista, retira as pessoas das ruas e aumenta a necessidade de vagas em comunidades terapêuticas e hospitais que possuem leitos para internação. Constitui-se, portanto, como violadora de direitos. No entanto, tem sido retratada como "ação humanitária", na medida em que desconsidera a autonomia do usuário ao impor esse modelo de tratamento, o que vai contra o princípio universal do Sistema Único de Saúde, o qual defende a autonomia do usuário em aderir ou não ao tratamento proposto (BRASIL/MS, 2004).

Considera-se que as experiências em saúde coletiva, com estratégias baseadas na política de redução de danos, com os "consultórios na rua" e tratamentos ambulatoriais propõem que o usuário faça seu tratamento próximo de seu ambiente e de suas relações familiares (GOMES; VECCHIA, 2018). Essa perspectiva é contrária ao encarceramento, visando a ampliação da rede de saúde e assistência, tendo em vista que a demanda do usuário de drogas difere da demanda de um usuário da saúde comum. O serviço dos Centros de Atenção Psicossocial, se abertos 24hs, facilitariam as acolhidas e abordagens aos usuários de drogas, mesmo durante a madrugada, com equipes especializadas para atender a esses sujeitos.

É necessário, portanto, que o Serviço Social brasileiro amplie o debate sobre o fenômeno do uso prejudicial de drogas, a fim de contribuir com seus conhecimentos sobre os diferentes paradigmas, posicionamentos e modelos que perpassam essa temática e, assim, ter condições de identificar a visão que mais se aproxime dos fundamentos éticos e políticos do projeto profissional. Ao posicionar-se contra a internação compulsória, resgata-se o arcabouço teórico e prático advindos de conquistas históricas na área da saúde mental, que têm se voltado contra medidas que violem direitos humanos, e que garantam respostas críticas e fundamentadas ética e teoricamente.

Há diferentes interesses que fomentam ações de cunho arbitrário e violento contra pessoas em situação de rua, usuários de drogas e sujeitos que residem em territórios nos quais existem conflitos advindos do tráfico de drogas. Dessa forma, o serviço social, orientado por seu projeto profissional e princípios, como, a ampliação e consolidação da cidadania, defesa intransigente dos direitos humanos e recusa do autoritarismo, tem sido solicitado a atuar na superação do imediatismo, senso comum e fragmentação que permeiam os espaços cotidianos de atuação profissional (CFESS, 1993). O documento do Conselho Nacional sobre Drogas, que dispõe sobre o Realinhamento dessa Politica (BRASIL/ CND, 2018) não demonstra rompimento com o caráter conservador e autoritário do Estado ao lidar com o uso prejudicial de drogas. A via da repressão foi largamente impulsionada pelo Estado, tendo em vista os investimentos públicos nas ações policiais repressivas, além do foco na 
construção de presídios como via de "solução". Foram reduzidos, enquanto isso, os investimentos em Educação e Saúde Pública. As ações higienistas nas cracolândias em diversos Estados do País são exemplos dessa perspectiva punitiva e autoritária (SILVA, 2014).

Algumas práticas baseiam-se na dependência de drogas como uma doença de trato biológico que necessita de tratamento e reabilitação, com foco centrado no sujeito e na redução da demanda. Os dispositivos de atenção que são orientados por essa perspectiva são os Alcoólicos Anônimos, Narcóticos Anônimos, entre outros. Nota-se que em alguns destes modelos ocorre uma aproximação ao modelo moral, quando se associa o uso prejudicial de drogas pelo prazer com a ideia de incapacidade da "razão". A meta que direciona esse modelo é a abstinência total, a partir da adoção de "doze passos" que tem a sobriedade como meta (LIMA; BRAGA, 2012).

A redução de danos busca o rompimento com a ideia do uso abusivo de drogas, ao afirmar que o uso que os sujeitos desenvolvem pode ou não ser prejudicial. Essas estratégias podem ser aplicadas a pessoas que não desejam ou não conseguem reduzir ou parar completamente o uso de drogas, assim como para os demais sujeitos que possuem dificuldades para ingressar ou aderir a tratamentos nos serviços de saúde.

\section{A polêmica política brasileira sobre as drogas}

No Brasil, os movimentos da Reforma Sanitária e Psiquiátrica, que eclodiram em meio à redemocratização do Estado na década de 1980, redirecionaram os modelos de atenção e gestão das práticas de saúde, voltando-se para a promoção da saúde coletiva, equidade na oferta de serviços e protagonismo dos sujeitos, usuários e trabalhadores da saúde nos processos de gestão. Particularmente, a Reforma Psiquiátrica surgiu inspirada no modelo italiano de superação da lógica asilar centrado no hospital psiquiátrico. A Reforma constituiu-se como um movimento político e social complexo, composto por inúmeros atores e instituições e que foi marcado por diversas tensões, conflitos e desafios. Sua total efetivação requer profundas mudanças culturais, e implica o estabelecimento de diálogos permanentes com a sociedade, a fim de que os sujeitos com transtornos mentais e/ou decorrentes do abuso e/ou dependência de drogas possam usufruir de uma rede de atenção integral as suas necessidades (MELLO; PAULON, 2015).

É preciso considerar, no entanto, que a sociedade civil, desde a década de 1940, já se organizava em espaços grupais de ajuda mútua como uma forma de tratamento e "recuperação" para usuários abusivos e/ou dependentes de drogas. Por meio de uma literatura que orienta "doze passos" em direção à abstinência, entre outros aspectos da vida da pessoa, os Alcoólicos Anônimos (AA), Narcóticos Anônimos, entre outros, foram se expandindo e funcionam, até os dias atuais, como alternativa de tratamento (BURNS; LABONIA FILHO, 2017).

O texto constitucional (BRASIL, 1988) traz o marco conceitual de Seguridade Social, conjunto integrado de ações de iniciativa dos Poderes Públicos e da sociedade, os quais se destinam a assegurar os direitos relativos à saúde, à previdência e à assistência social. A partir da nova perspectiva da saúde, junto ao movimento da Reforma Psiquiátrica, foi possivel rever antigas práticas e avançar na materialização de novas formas de atenção. Além disso, torna-se essencial que as políticas sociais sejam pautadas em uma lógica intersetorial em sua gestão, pressupondo a articulação entre diversos setores das diferentes políticas. A intersetorialidade prevê a articulação de saberes e experiências no centro do processo de gerenciamento dos poderes públicos em resposta às demandas da população e pressupõe a não fragmentação das políticas sociais (PEREIRA, 2004).

As políticas públicas podem ser compreendidas como espaço de tomada de decisão autorizada por meio de atores governamentais, abrangendo ações que tornem viáveis agendas de inovação em políticas ou que respondam a demandas de grupos de interesse (COSTA, 1998). A consolidação do Estado brasileiro determinou 
as caracteristicas e temporalidade das políticas de saúde e assistência social ao longo do século XX. A mudança no conceito de saúde, presente na constituição (BRASIL, 1988), influenciou na reconfiguração do processo saúde-doença, assim como, foram repensados os diferentes desafios na área da atenção à saúde, os quais geram impactos também na proteção social. A partir dessa mudança, foi possivel rever antigas práticas e avançar na materialização de novas formas de atenção, a partir dos direitos das pessoas com sofrimento psíquico e a previsão de extinção dos manicômios, contra o modelo hospitalocêntrico, até então, hegemônico. (BRASIL, 2001).

Em 2002 o Ministério da Saúde lançou o Programa Nacional de Atenção Comunitária Integrada aos usuários de álcool e outras drogas (BRASIL, 2002a), o qual se constituiu como marco na construção das políticas nessa área, no âmbito da saúde mental. O referido programa buscou a articulação de ações pelas três esferas do governo voltadas à promoção da atenção a pessoas com "dependência e/ou uso prejudicial de álcool ou outras drogas". Foi lançada, também, a Política Nacional Antidrogas (BRASIL, 2002b), com ênfase no eixo da prevenção ao uso "indevido" de drogas e o tratamento na perspectiva humanizada.

A política específica foi lançada em 2004, sob o nome de Política de Atenção ao Usuário de Álcool e outras Drogas (BRASIL, 2004). Essa política traz consigo a lógica intersetorial, tendo em vista o reconhecimento de que o consumo de drogas é transversal a diferentes áreas e requer atenção integral aos usuários e seus familiares. Além disso, a redução de danos aparece como diretriz do cuidado, colocando o usuário como protagonista de seu projeto terapêutico, fato importante, pois essas estratégias passam a integrar o conjunto de tratamentos a serem prestados a essa população. Dessa forma, a redução de danos "reconhece cada usuário em suas singularidades, traça com ele estratégias que estão voltadas não para a abstinência, como objetivo a ser alcançado, mas para a defesa de sua vida" (BRASIL, 2003, p. 10).

O modelo da redução de danos visa a participação ativa do sujeito na construção do seu projeto terapêutico, considerando suas singularidades e desejos que realmente the façam sentido. O usuário, como protagonista de seu processo de tratamento, é uma diretriz dessa estratégia, configurando-a como potencializadora nos processos de produção de saúde, cuidado e cidadania. Durante muitas décadas, a visão que a sociedade tinha dos usuários de drogas era altamente estigmatizante, voltando suas práticas para a repressão e exclusão social desses sujeitos. Esse cenário contribuía para a ruptura dos vínculos sociais, colaborando para a construção da imagem de pessoas autodestrutivas, fortemente atribuida a essa população. Abordagens repressivas eram adotadas em detrimento de processos educativos e que respeitassem o usuário como sujeito de direitos, passível de ter voz ativa sobre seu próprio tratamento.

O rompimento dessa perspectiva de isolamento dos sujeitos foi ocorrendo a partir do movimento da Reforma Psiquiátrica e suas proposições de práticas interventivas antimanicomiais. A Rede de Atenção aos Usuários de Drogas, ao ser instituida, foi ao encontro da perspectiva de desinstitucionalização e criou os serviços de Residencial Terapêutico e o Programa de Volta pra Casa, além de estratégias de reabilitação psicossocial (BRASIL, 2011). Com a instituição da rede, o hospital psiquiátrico seria retirado do posto de principal serviço de atenção à saúde mental, passando os dispositivos de cuidado mencionados, as internações necessárias e demais recursos para o adequado suporte às necessidades dos usuários de drogas e seus familiares.

O cenário nacional de precarização das políticas públicas, entretanto, vem atravessando o Brasil e, também, o estado do Rio Grande do Sul, culminando no fechamento e descontinuidade de muitos serviços, incluindo os dispositivos de atenção na área da saúde mental e drogas. Dessa forma, a defesa da esfera pública das politicas sociais e da proteção social constitui-se como grande desafio a ser enfrentado, contra a mercantilização e privatização dos serviços públicos, em direção à universalização e democratização do acesso aos direitos sociais da população (RAICHELIS, 2013). 
A crise enfrentada na área da saúde, que culmina na falta de recursos públicos e atinge a estrutura dos serviços, perpassa as demais esferas das políticas públicas, tendo em vista que a raiz da crise encontra-se no sistema econômico vigente, impactando toda a sociedade. Ocorrem, nesse cenário, o avanço e fortalecimento do mercado privado e o sucateamento do aparato público (ALENCAR, 2009).

Em 2006 foi instituido o Sistema Nacional de Políticas Públicas sobre Drogas, apontando para a prevenção ao uso indevido de drogas, a atenção e a reinserção social de usuários e dependentes de drogas estabelecendo metas para a repressão à produção de drogas (BRASIL, 2006). Em 2007 foi aprovada a Política Nacional sobre Álcool e outras Drogas, dispondo sobre medidas em direção à redução do uso indevido de álcool e sua relação com violência e criminalidade, trazendo novas regulamentações quanto às propagandas de bebidas alcoólicas, monitoramento e fiscalização, entre outros (BRASIL, 2007). Em 2010 foi lançado o Plano Integrado de Enfrentamento ao Crack e outras Drogas, também com eixos de prevenção, tratamento, reinserção social e enfrentamento ao tráfico (BRASIL, 2010).

Na IV Conferência Nacional de Saúde Mental Intersetorial, realizada em 2010, a política sobre drogas foi examinada, tendo sido deliberado o conjunto de principios que devem orientar as ações do Estado nessa área, principalmente no que tange a articulação entre as politicas sociais. Foi definido que as políticas públicas deveriam ser elaboradas integralmente, prevendo ações e financiamento na lógica intersetorial, especialmente, nos campos da infância e juventudes e no campo do uso abusivo de álcool e outras drogas. As deliberações reafirmam as diretrizes do Sistema Único de Saúde de atenção aos usuários de drogas nos três niveis de atenção (BRASIL, 1990), bem como as ações do Sistema Único de Assistência Social (BRASIL, 1993), as diretrizes e princípios da Política Nacional de Direitos Humanos (BRASIL, 2009), e do Programa de Atenção Integral a Usuários de Álcool e outras Drogas (BRASIL/MS, 2004). Além disso, as deliberações salientam a necessidade de efetivar as estratégias de redução de danos como política pública de saúde, e a ampliação da rede de saúde mental em território nacional (BRASIL, 2010).

A principal diretriz da Política Nacional de Saúde Mental consiste na redução organizada e gradativa de leitos em hospitais psiquiátricos, buscando a desinstitucionalização de pessoas em longo periodo de internação. A proposta é constituir uma rede de serviços e dispositivos assistenciais diversificada no âmbito da saúde mental, com base comunitária (MINOZZO et al., 2017, p. 14).

A reconfiguração do modelo de atenção em saúde mental objetivou qualificar o cuidado às pessoas com sofrimento psíquico e transtornos mentais, usuários de drogas e seus familiares. A atualização nesse modelo de atenção incluiu serviços comunitários e a base passou a ser territorial. Dessa forma, a atenção hospitalar deixa de ocupar a centralidade no cuidado à saúde, como era anteriormente, tornando-se complementar - o que retrata mudanças fundamentais na concepção de cuidado, pois implica compreender a importância da proximidade do usuário em tratamento de sua rede familiar, social e cultural, para que seja possivel a reapropriação no protagonismo em seu processo de saúde/ adoecimento (BRASIL, 2001)

Os serviços constituintes da Rede de Atenção Psicossocial são diversos e passam pela Atenção Básica em Saúde por meio da Estratégia de Saúde da Familia (ESF), do Núcleo de Apoio à Saúde da Família (NASF) e do Centro de Convivência e Cultura. Para contemplar a atenção psicossocial estratégica, foram criados os Centros de Atenção Psicossocial (CAPS), e, para atenção de caráter transitório, as Unidades de Acolhimento. A atenção hospitalar é voltada para as urgências por meio do Serviço de Atendimento Móvel de Urgência (SAMU), Unidade de Pronto Atendimento (UPA), e por meio de um serviço hospitalar ou Enfermaria Especializada em Hospital Geral, conforme determinado pela legislação (BRASIL, 2011).

Cabe destacar o trabalho das Equipes de Consultório na Rua e suas ações voltadas para atenção integral à saúde de usuários em situação de rua. Norteadas pela estratégia da redução de danos, 
no âmbito da saúde mental para usuários que fazem uso prejudicial de drogas, realizam abordagens de forma itinerante, buscando locais nos quais os sujeitos costumam se reunir. Desenvolvem ações integradas às Unidades de Saúde, Centros de Atenção Psicossocial, Serviços de Urgência e Emergência, entre outros, tendo em vista as dificuldades dessa população em acessar os serviços de saúde. Esse trabalho, no entanto, sofreu com a precarização das politicas públicas, as quais reduziram seus recursos materiais e humanos para a realização do trabalho. Avalia-se que este tipo de trabalho, por atuar diretamente nos territórios e locais de uso dos sujeitos, é gerador de potencialidade na aproximação da rede com o território, e demonstra a importante função do redutor de danos nesse cenário (ADAMY et al., 2014). Além disso, a mudança na nomenclatura de "Consultório de Rua" para "Consultório na Rua" implicou na alteração do que consistia a caracterização desse serviço, o qual ampliou suas ações para além da atenção em saúde mental, dirigindo-se para a atenção à saúde da população em situação de rua de forma geral. Ainda assim, foi mantida a estratégia da redução de danos, aparecendo então como diretriz na atenção básica, conforme preconizado pela Política Nacional de Atenção Básica (BRASIL, 2017).

Salienta-se que há uma relação entre o nivel maior de desigualdade em certos territórios e o uso prejudicial e/ou dependência de drogas, assim como a ocorrência de situações de violência (ADAMY et al., 2014). No entanto, a violência não é necessariamente atrelada ao consumo, e sim guarda maior relação com as disputas territoriais do tráfico de drogas. Dessa forma, para o planejamento das políticas públicas sobre drogas é necessário romper com estigmas de que o único padrão de uso é o abusivo e que este geraria "automaticamente" a dependência, e que essas pessoas uma vez dependentes, também se tornam causadoras da violência urbana. Ou seja, é preciso compreender o uso de drogas como um fenômeno em toda sua complexidade.

A redução de danos é alicerçada em três importantes aspectos, quais sejam: a não exigibilidade da abstinência; ${ }^{4}$ o direito de participação política das pessoas que usam drogas e a potencialidade do trabalho nos territórios organizado em horários estratégicos. Assim, se tornam possiveis medidas no âmbito da saúde pública que visem reduzir os efeitos adversos do uso abusivo e/ou dependência de drogas por meio da construção de vínculos e ações de cuidado, mas também de autocuidado, buscando preservar a autonomia e liberdade de escolha dos sujeitos frente as suas possibilidades de tratamento (PETUCO; MEDEIROS, 2010).

Ao encontro da perspectiva de desinstitucionalização, a rede definiu os serviços de Residencial Terapêutico, Programa de Volta para a Casa, além de estratégias de reabilitação psicossocial (BRASIL, 2011). O cenário da rede no Estado do Rio Grande do Sul está atravessado pelo cenário nacional de precarização das politicas públicas, o que culmina com o fechamento e descontinuidade de muitos serviços, incluindo os dispositivos de atenção na área da saúde mental e drogas. Dessa fora, a defesa da esfera pública das políticas sociais e da proteção social constitui-se como grande desafio a ser enfrentado, contra a mercantilização e privatização dos serviços públicos, em direção à universalização e democratização do acesso aos direitos sociais da população (RAICHELIS, 2013).

Os Municipios de porte médio dispõem de Centros de Atenção Psicossocial Álcool e outras Drogas (CAPS AD) e Comunidades Terapêuticas. As Comunidades Terapêuticas (CTs), em sua grande maioria, possuem vinculos religiosos e os utilizam como condicionantes para o tratamento. Embora possuam caráter privado, oferecem algu-

\footnotetext{
4 A Organização Mundial de Saúde aborda a dependência química como o "estado psíquico" e algumas vezes físico que resulta da interação entre um organismo e uma substância, a qual caracteriza modificações no comportamento e outras reações que incluem o impulso pelo uso contínuo da substância ou uso periódico, a fim de buscar seus efeitos psíquicos e, algumas vezes, para evitar o desconforto resultante da privação do uso da substância. Ressalta, ainda, que além de ser uma doença crônica, deve ser tratado como problema social, uma vez que importa também identificar as consequências e motivos que levam ao uso prejudicial da substância, compreendendo os sujeitos em sua totalidade, para que se possam encontrar subsídios que auxiliem no tratamento de forma integral (OMS, 2001).
} 
mas poucas vagas oriundas de convênios com os municípios. As dificuldades para regulamentação das comunidades dificultam, também, as formas de avaliação e vigilância desse serviço no âmbito da politica de saúde. Gestores desses locais solicitam maior apoio financeiro até mesmo para conseguirem enquadrar-se nas normas, enquanto dispositivos de cuidado em saúde, pois, normalmente, dependem de doações e/ou recebem pagamentos de usuários e seus familiares.

As Comunidades Terapêuticas frequentemente são alvos de denúncias por violações de direitos humanos. Em 2015, foi lançada uma resolução que vincularia essas instituições ao Ministério da Justiça, passivel de receber recursos diretamente da Secretaria Nacional da Política sobre Drogas (BRASIL, 2015), a qual buscava que as entidades não fossem reconhecidas como entidades de saúde, o que fragilizaria o processo de fiscalização desses serviços e o cumprimento das exigências concernentes à saúde. Nesse sentido, a Secretaria de Atenção à Saúde editou a Portaria $n^{\circ} 1.482$, a qual determinou a inclusão desses serviços como dispositivos de saúde no Cadastro Nacional de Estabelecimentos de Saúde (BRASIL, 2016a). Essa inclusão aumenta as chances de as entidades conseguirem recursos do SUS, tornando possivel, também, o aumento das formas de fiscalização.

No ano de 2019, o governo Bolsonaro aprovou a "nova" Política Nacional de Drogas, por meio do Decreto 9761 (BRASIL, 2019). O texto aprovado dispõe especialmente sobre a adoção da abstinência total como diretriz, em substituição à redução de danos. Além disso, pauta abertamente o incentivo e expansão das comunidades terapêuticas por meio de incentivos financeiros, deixando claro o caminho da mercantilização da saúde e retrocesso da luta antimanicomial.

A lei de drogas brasileira tem atuado, historicamente, na premissa punitiva e o tem feito de maneira muitas vezes equivocada. Tal afirmação baseia-se no fato de que o regime de cumprimento de pena tem impulsionado uma das maiores populações carcerárias no âmbito mundial, com 20\% dos detentos respondendo por tráfico de drogas; ou seja, o correspondente a uma população carcerária de mais de 200 mil pessoas em 2019 (BRASIL/MJ, 2019). Ressalta-se que a posse para consumo pessoal, mesmo atribuída a medidas alternativas, ainda é permeada por estigma criminal e pode ocasionar a perda da primariedade. Nota-se que a política de drogas tem participado como propulsora de desigualdades de raça, gênero e classe, ou seja, alicerçada no proibicionismo, tem garantido a exclusão, aprisionamento e morte de determinadas pessoas. É este o caminho que tem sido consolidado pelo governo atual na condução da politica de drogas no País, com diretrizes mais excludentes e violentas, bradando a defesa do encarceramento em detrimento do cuidado.

A pauta conservadora tem avançado, sendo definido o protagonismo da abstinência total e internações como forma privilegiada de tratamento e fomento às comunidades terapêuticas. Dessa forma, nota-se que o endurecimento da política de drogas e do encarceramento caracterizam o Estado que, ancorado em seus três poderes, reproduz a lógica punitivista. Essa lógica aposta na falida "guerra às drogas" e no proibicionismo, mantendo o aprisionamento e violência letal de pessoas, enquanto gera lucros e fomenta o crescimento de instituições asilares e manicomiais.

\section{A rede de atenção psicossocial}

Na avaliação quanto ao cuidado ofertado pelas comunidades terapêuticas no Estado, os usuários apontaram a dificuldade de se manter longe da família e da sua rede social comunitária, o que foi visto por eles como impactos negativos em seu tratamento. As comunidades oferecem tratamentos de longo período de internação, normalmente de seis meses a um ano. Além disso, existem controvérsias quanto à sua modalidade de atuação. Os serviços dos residenciais terapêuticos descritos na portaria da RAPS devem possuir caráter transitório (BRASIL, 2011) e seriam os substitutivos à lógica da internação prolongada em que não havia previsão de retorno à realidade dos sujeitos. A implementação dos residenciais terapêticos esbarra, no entanto, 
em impasses de diversas ordens, por parte do Estado e dos municipios. Ponto relevante para essa discussão é a Portaria n 8 de 2018, fruto da Secretaria Nacional de Politicas sobre Drogas, a qual busca constituir uma Comissão Especial de Avaliação, encarregada de trabalhar no âmbito dos contratos com prestadores de serviços de acolhimento a pessoas em tratamento por abuso e/ou dependência de drogas, ou seja, as comunidades terapêuticas (BRASIL, 2018a). Está prevista, dessa forma, a avaliação dos serviços para que atendam às normas exigidas para seu funcionamento adequado, conforme dispõem as diretrizes do cuidado à saúde do usuário de drogas nas diversas políticas que tratam da questão.

Os serviços acessados com maior frequência pelos usuários entrevistados foram respectivamente: os CAPS, os hospitais para o periodo de internação/desintoxicação, seguidos dos grupos de mútua ajuda, como os Alcoólicos Anônimos e Narcóticos Anônimos, e fazendas ou comunidades terapêuticas. Nesse cenário, mais de 82\% dos gestores dos serviços, em diferentes modalidades de atendimento (CAPS, hospital, comunidade terapêutica, entre outros), avaliaram a rede de atenção disponivel em seu municipio como insuficiente para a demanda. Além disso, na avaliação de $76 \%$ dos trabalhadores da rede desses municipios a cobertura dos serviços foi concebida como "parcial" ou "insuficiente" para atender as necessidades existentes. Salienta-se, nesse sentido, que muitas cidades contam apenas com Unidades Básicas de Saúde (UBS) e grupos de ajuda mútua, pois não se enquadram no critério para a construção de CAPS, pois estes são distribuidos nacionalmente conforme recorte populacional (BRASIL, 2011).

Quanto à qualidade dos serviços disponíveis nos municípios, $60 \%$ dos usuários e $62,5 \%$ de seus familiares classificaram como ótima ou boa. Contudo, aqueles que consideram insatisfatória a qualidade dos serviços (usuários - $24,4 \%$; familiares $-18,75 \%$ ) solicitaram o aumento da oferta e qualificação para os profissionais em atuação na área da saúde mental. Dentre as dificuldades de trabalhar nessa área, está a heterogenia nas perspectivas e visões sobre o tema, as quais, "[...] atingem, em últimas instâncias, o profissional e o usuário, que por sua vez, já são influenciados por seus valores e crenças" (COSTA et al., 2015. p. 60), dificultando um atenção homogênea no que diz respeito à essa área.

A partir dessas avaliações, compreende-se a necessidade de expandir os serviços, especialmente os serviços de CAPS 24 horas, os quais devem possuir capacidade técnica para regular a porta de entrada da rede assistencial em seu território e/ou módulo assistencial e constituir-se como serviço ambulatorial de atenção contínua (BRASIL, 2002a). Além disso, os serviços tipificados como CAPS AD III são pontos de atenção especializada para pessoas com necessidades relacionadas ao consumo de álcool, crack e outras drogas, com funcionamento nas 24 horas do dia, inclusive finais de semana e feriados (BRASIL, 2012).

Até o ano de 2014, no entanto, somente 2.209 CAPS se encontravam em funcionamento no país, e desses, apenas 85 funcionavam no período de 24 horas (GOMES, 2017). Essa realidade está relacionada com o baixo investimento em serviços substitutivos à lógica hospitalocêntrica, combatida pela reforma psiquiátrica, demonstrando as dificuldades ainda encontradas para a sua efetivação. Enquanto isso, as comunidades terapêuticas e clínicas particulares fortalecem suas estratégias privatistas de internação, regressando aos modelos antigos de atenção em saúde mental.

São reconhecidos os avanços presentes no âmbito da política em saúde mental com atenção a usuários de drogas em âmbito nacional, no entanto, para a plena implementação e consolidação da reforma psiquiátrica, ainda é necessária a vontade política dos governos locais. A construção da política não se dá de forma linear e passa por diferentes obstáculos tanto de cunho teórico, no que concernem as diferentes linhas aplicadas por seus atores quanto ao tratamento, e também pela necessidade da intersetorialidade, exigida pela complexidade do fenômeno do consumo de drogas na sociedade. Nesse sentido, usuários apontaram que o atendimento era insuficiente para o volume da demanda, indicando como difi- 
cultador, também, a rotatividade de profissionais que os atendiam. O prejuízo estava na dificuldade de construção de vínculos desses usuários com os profissionais e serviços.

Outro ponto importante que surgiu na pesquisa foi a necessidade de qualificar o acompanhamento após o processo de tratamento, especialmente no que visa a inserção dos usuários no mercado de trabalho e na reconstrução de suas atividades e laços sociais. A construção do projeto de vida para retomada das atividades após o tratamento de internação ou durante o acompanhamento em CAPS deve considerar pontos importantes, tais como: continuidade do tratamento, mudança no estilo de vida, metas tangiveis, estabelecimento e/ou resgate da rede social e rede de apoio. A elaboração do projeto de vida implica em ações contínuas que devem interligar-se de forma harmônica, com vistas ao resgate da rede social do sujeito (DUARTE, 2017).

Nesse sentido, destaca-se a importância da rede e do matriciamento em saúde mental. Em consonância com o princípio da integralidade do SUS, o matriciamento visa qualificar e ampliar as ações das equipes da Atenção Básica e aproximar-se das Equipes de Estratégia de Saúde da Familia (ESF). Aparece como alternativa contra a fragmentação das práticas de cuidado, buscando a união dos saberes entre as equipes para potencializar as intervenções no âmbito da saúde (CAMPOS; DOMITTI, 2007).

No que diz respeito aos profissionais envolvidos nos tratamentos, os usuários fizeram referências positivas, por ordem de frequência, à vinculação com psicólogos, médicos psiquiatras e assistentes sociais, seguidos de enfermeiros e técnicos de enfermagem. Evidencia-se, assim, a importância de equipes multidisciplinares e interdisciplinares, que estão previstas pela política de atenção.

Os usuários identificaram diversas dificuldades em manter o tratamento, como: problemas em lidar com as recaídas; por exclusão social; pela discriminação no ambiente de trabalho e em outros grupos de convivência; por autoexclusão; pela aparência física deteriorada; por situação econômica ruim; pelo reconhecimento de proble- mas emocionais, afetivos com a familia e consigo mesmo; mas principalmente familiar e financeiro. Afirmam que a familia seria fator determinante para auxiliar na mudança de vida. Os relatos de usuários, sobre suas trajetórias de vida e nos serviços, demonstram a dificuldade de permanecer no tratamento, pois, sem o devido apoio sociofamiliar, dificilmente, visualizam avanços significativos em seus tratamentos.

Os tratamentos e seu caráter multidisciplinar e integrado, conforme as normativas devem envolver orientação familiar, prevenção de recaída e reinserção social e familiar do usuário. Além disso, o acompanhamento deve incluir orientação em relação às recaídas, à efetividade, comunicação e compreensão do papel de cada um em seu contexto familiar. Dessa forma, é importante a busca da família na participação do tratamento, devendo esta ser acolhida, orientada e motivada para tal (SILVA, 2017).

Foram diversos os desafios identificados para a efetivação da RAPS, tanto no macro quanto nos âmbitos micropolíticos. A luta constante presente no movimento antimanicomial se mantém na busca por melhores condições de trabalho, na "garantia da territorialidade, gestão compartilhada, buscando atenção de maior qualificação aos usuários, o trabalho em rede e o protagonismo dos atores sociais envolvidos no processo" (ELY, 2017, p. 362).

Um exemplo do desmonte na área das drogas é a aprovação da resolução do Conselho Nacional sobre Drogas 01/2018 (BRASIL, 2018b), que redireciona a política de drogas no país, retrocedendo na abordagem aos usuários por retomar as estratégias focadas na abstinência como ênfase de tratamento. Essa resolução caminha contra todo o avanço até então estabelecido pela atenção psicossocial e as estratégias de redução de danos. Assim, retomam-se os discursos de terceirização dos serviços uma vez que o âmbito da internação passa a figurar como forte instrumento de tratamento, privilegiando as comunidades terapêuticas.

Os direitos humanos devem ser considerados como a matriz ética orientadora do marco legal das políticas sobre drogas no país. Deve haver, 
portanto, o esforço de ultrapassar o senso comum e promover o debate sobre os direitos fundamentais como marco para a vida digna de todos e cada pessoa. Não é incomum que os direitos humanos sejam tratados de forma simplista, vindo à tona em debates envolvendo comoção pública, nos quais se relacionam a defesa desses direitos como a defesa dos direitos dos "bandidos". Essa leitura largamente explorada pela midia em investidas sensacionalistas se sobrepõe à compreensão política, ampla e inclusiva do real significado dos direitos humanos. Na perspectiva das drogas, a defesa dos direitos humanos requer o repúdio a qualquer tipo de violência e preconceito, devendo orientar-se pela garantia do sujeito de poder decidir sobre seu próprio tratamento, ou seja, não está em consonância com os processos de internação compulsória, os quais negligenciam os direitos fundamentais da pessoa humana (OLIVEIRA, 2017).

O debate com a sociedade, usuários e trabaIhadores dessa rede, fundamentados por suas experiências, vivências, em consonância com acadêmicos que se dedicam a essa temática é imprescindivel para que não ocorra o retrocesso nas políticas sobre drogas. O fortalecimento da participação social é poderoso instrumento frente a crise do capital, que busca cada vez mais mercantilizar as relações sociais de todas as formas.

Nesse aspecto, uma política de direitos humanos, ao contrário do sugerido pelo senso comum, passa a ser, fundamentalmente, um paradigma que defende e promove incondicionalmente a vida e a dignidade humana, sendo uma abordagem preventiva aos desmandos, aos modismos, aos preconceitos, aos fundamentalismos.

\section{Considerações finais}

O Estado brasileiro tem sofrido com o desmonte dos direitos sociais por meio da adoção de uma agenda neoliberal, conservadora com faces radicais que atacam as conquistas sociais presentes na Constituição Federal. Esses ataques são frutos da reorganização do capital financeiro, o qual vem impondo a precarização em diferentes âmbitos da vida em sociedade. É nesse cenário que se percebe a restrição da competência do Estado no âmbito das politicas sociais, as quais se encontram cada vez mais fragmentadas. A política sobre drogas, especialmente no âmbito da saúde mental, também sofre os rebatimentos desse cenário de crise.

Ao mapear e analisar a legislação brasileira sobre drogas e o processo de construção da Rede de Atenção Psicossocial no Rio Grande do Sul, diversos foram os apontamentos que emergiram no estudo. Foi identificada, também, a investida da mercantilização da saúde, e a importância da luta constante pela garantia do financiamento público para as ações nas áreas sociais, contra a privatização e contra o desmonte dos direitos sociais. Foi percebida, também, a necessidade de iniciativas para capacitação dos profissionais para atuarem na área das drogas. Considera-se de extrema importância a participação social nos processos decisórios e de gestão das políticas sociais para uma efetiva fiscalização das políticas e serviços ofertados.

Evidenciou-se, neste estudo, a importância da integralidade na oferta e acesso às políticas, bem como a intersetorialidade como pilar para atingir a atenção integral aos usuários. Destaca-se a redução de danos como potencial estratégia de tratamento, tendo em vista a proximidade com os usuários em seus próprios territórios e locais de uso de drogas. Implica, também, a necessidade de ressignificar os territórios marcados por violência, para territórios com espaços de circulação e lazer, entre outras atividades para a comunidade. Nesse sentido, o posicionamento contrário a práticas focadas somente na abstinência como tratamento é emergente, uma vez que muito já se avançou com a perspectiva da redução de danos e suas estratégias que se aproximam do usuário e, acima de tudo, o respeitam como sujeito principal e atuante no seu próprio tratamento.

Além disso, trata-se de enxergar as investidas do mercado em direção à internação de usuários como forma lucrativa, sob as vestes de "melhor opção para tratamento", perdendo de vista todo avanço substanciado em pesquisas científicas e diversos estudos que fundamentam os pilares da Reforma Psiquiátrica, especialmente frente aos desmontes promovidos pelo governo Bolsonaro 
na luta antimanicomial, com retrocessos graves na atenção à saúde mental no Brasil.

O âmbito micropolítico da rede é constituido por fluxos entre os trabalhadores, assim, concebe-se que a rede é relacional e não somente o conjunto de serviços. Gestores e trabalhadores das políticas públicas devem voltar à centralidade de suas ações para a população usuária, ao pensar normas, processos, serviços e atendimentos. Ao sujeito deve ser garantida a liberdade de decidir sobre seu tratamento, tendo respeitados seus desejos e singularidades, como participante principal na construção do seu plano terapêutico. Dessa forma, avistam-se perspectivas que garantam os direitos fundamentais dos usuários de drogas, com atenção integral e qualificada às suas demandas.

\section{Referências}

ADAMY, Paula Emília et al. Cuidado, protagonismo e diálogos intersetoriais: o que pensa um território sobre as políticas para álcool e outras drogas. In: DALMOLIN, Maria Bernadete; DORING, Marlene (org.). Crack e outras drogas: múltiplas facetas do cuidado em saúde mental. Passo Fundo: Universidade de Passo Fundo, 2014.

ALENCAR, Mônica. O trabalho do assistente social nas organizações privadas não lucrativas. In: Conselho Federal de Serviço Social (CFESS). Associação Brasileira de Ensino e Pesquisa em Serviço Social (ABEPSS). Serviço Social: Direitos Sociais e Competências Profissionais. Brasilia: CFESS, 2009. p. 524-538.

ANDRADE, Tarcisio Matos de.; RONZANI, Telmo Mota. A estigmatização associada ao uso de substâncias como obstáculo à detecção, prevenção e tratamento. In: FORMIGONI, Maria L. O. S.; DUARTE, Paulina C. A. V (org.). O Uso de Substâncias Psicoativas no Brasil: módulo 1. 11. ed. Brasilia: Secretaria Nacional de Políticas sobre Drogas. 2017. p. 31-45.

BAUER, Martin W:; GASKELL, George. Pesquisa qualitativa com texto, imagem e som: um manual prático. Petrópolis: Vozes, 2002.

BEHRING, Elaine R. Brasil em contrarreforma: desestruturação do Estado e perda de direitos. São Paulo: Cortez, 2003

BOGDAN, Robert; BIKLEN, Sari. Investigação qualitativa em educação. Porto: Porto Editora, 1994.

BRASIL. IConstituição (1988)]. Constituição da República Federativa do Brasil. Brasilia, DF: Senado Federal, 1988.

BRASIL. Lei n 8.080, de 19 de setembro de 1990. Dispõe sobre a proteção e recuperação da saúde, a organização e o funcionamento dos serviços correspondentes e dá outras providências. Diário Oficial da União: Brasília, 1990.
BRASIL. Lei n 10.216 , de 6 de abril de 2001. Dispõe sobre a proteção e os direitos das pessoas portadoras de transtornos mentais e redireciona o modelo assistencial em saúde mental. Diário Oficial da União: Brasilia, 2001

BRASIL. Portaria $n^{\circ}$ 816, de 30 de abril de 2002b. Instituir, no âmbito do Sistema Único de Saúde, o Programa Nacional de Atenção Comunitária Integrada a Usuários de Álcool e Outras Drogas. Brasília, DF: Ministério da Saúde, 30 abr. 2002. Disponivel em: http://bvsms.saude.gov

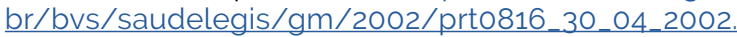
html. Acesso em: 27 jun. 2018

BRASIL. Decreto $n^{\circ} 4.345$, de 26 de agosto de $2002 \mathrm{c}$. Política Nacional Antidrogas. Brasilia, DF: Presidência da República, 26 ago. 2002. Disponivel em: http://www. planalto.gov.br/ccivil_03/decreto/2002/d4345.htm. Acesso em: 14 jun. 2018.

BRASIL. Ministério da Saúde. Portaria n³36, de 19 de fevereiro de 2002. Estabelecer que os Centros de Atenção Psicossocial pudessem constituir-se nas seguintes modalidades de serviços: CAPS I, CAPS II e CAPS III. Brasilia, DF: Ministério da Saúde, 19 fev. 2002 Disponivel em: http://bvsms.saude.gov.br/bvs/saudelegis/gm/2002/ prt0336_19_02_2002.html. Acesso em: 27 jun. 2018.

BRASIL. Ministério da Saúde. Secretaria Executiva Coordenação Nacional de DST/Aids. A Politica do Ministério da Saúde para atenção integral a usuários de álcool e outras drogas. Ministério da Saúde, Secretaria Executiva, Coordenação Nacional de DST e Aids. Brasília: Ministério da Saúde, 2003.

BRASIL.S.E.D.H.P.R. Decreto $n^{\circ}$ 7.037, de 21 de dezembro de 2009. Aprova o Programa Nacional de Direitos Humanos e dá outras providências. Diário Oficial da União: Brasília, DF, 2009.

BRASIL. Lei $n^{\circ} 11.343$, de 23 de agosto de 2006. Sistema Nacional de Políticas Públicas sobre Drogas (SISNAD). Brasilia, DF: Presidência da República, 2006. Disponivel em: http://Www.planalto.gov.br/ccivil_03/_ato20042006/2006/lei/l11343.htm. Acesso em: 14 jun. 2018.

BRASIL. Decreto $n^{\circ}$ 6.117, de 22 de maio de 2007. Política Nacional sobre o Álcool. Brasília, DF: Presidência da República, 2007.Disponivel em: http://www.planalto. gov.br/ccivil_03/_ato2007-2010/2007/decreto/d6117. htm. Acesso em: 14 jun. 2018.

BRASIL. Decreto $n^{\circ} 7.179,20$ de maio 2010. Plano Integrado de Enfrentamento ao Crack e outras Drogas. Brasilia, DF: Presidência da República, 2010. Disponível em: http://www.planalto.gov.br/ccivil_03/_ato20072010/2010/decreto/d7179.htm. Acesso em: 14 jun. 2018.

BRASIL. Ministério da Saúde. Portaria n 3.088, de 23 de dezembro de 2011. Institui a Rede de Atenção Psicossocial para pessoas com sofrimento ou transtorno mental e com necessidades decorrentes do uso de crack, álcool e outras drogas, no âmbito do Sistema Único de Saúde (SUS). Brasília, DF: Presidência da República, 2011. Disponivel em: http://bvsms.saude.gov.br/bvs/ saudelegis/gm/2011/prt3088_23_12_2011_rep.html. Acesso em: 14 jun. 2018 
BRASIL. Ministério da Saúde. Portaria $n^{\circ} 130$, de 26 de janeiro de 2012. Redefine o Centro de Atenção Psicossocial de Álcool e outras Drogas 24 h (CAPS AD III) e os respectivos incentivos financeiros. Brasilia, DF: Presidência da República, 2012. Disponivel em: http://bvsms.saude.gov.br/bvs/saudelegis/gm/2012/ prt0130_26_01_2012.html. Acesso em: 15 jun. 2018.

BRASIL. Ministério da Saúde. Portaria $n^{\circ}$ 1.482, de 25 de outubro de 2016a. Inclui na Tabela de Tipos de Estabelecimentos de Saúde do Cadastro Nacional de Estabelecimentos de Saúde - CNES o tipo 83 - Polo de Prevenção de Doenças e Agravos de Promoção da Saúde. Disponivel em: http://bvsms.saude.gov.br/ bvs/saudelegis/sas/2016/prt1482_25_10_2016.html. Acesso em: 15 jun. 2018.

BRASIL [Constituição (1988)]. Emenda Constitucional $n^{\circ}$ 95, em 15 de dezembro de 2016. Altera o Ato das Disposições Constitucionais Transitórias, para instituir o Novo Regime Fiscal, e dá outras providências. Diário Oficial da União: Brasília, DF, p. 2, col. 2, 16 dez. 2016.

BRASIL. Lei n 13.341, de 29 de setembro de 2016. Dispõe sobre a organização da Presidência da República e dos Ministérios. Brasilia, DF: Presidência da República, 2016. Disponivel em: http://www.planalto.gov.br/ ccivil_03/_ato2015-2018/2016/lei/L13341.htm. Acesso em: 29 de jun. 2018.

BRASIL. Lei no 13.429, de 31 de março de 2017. Altera dispositivos da Lei no 6.019, de 3 de janeiro de 1974 , que dispõe sobre o trabalho temporário nas empresas urbanas e dá outras providências; e dispõe sobre as relações de trabalho na empresa de prestação de serviços a terceiros. Brasilia, DF: Presidência da República, 2017. Disponivel em: http://wwww.planalto. gov.br/ccivil_03/_ato2015-2018/2017/lei/L13429.htm. Acesso em: 29 jun. 2018.

BRASIL. Lei $n^{\circ}$ 13.467, de 13 de julho de 2017. Altera a Consolidação das Leis do Trabalho (CLT). Brasilia, DF: Presidência da República, 2017. Disponivel em: http:// www.planalto.gov.br/ccivil_03/_ato2015-2018/2017/ lei/L13467.htm. Acesso em: 25 set. 2018.

BRASIL. Ministério da Saúde. Portaria no 2.436, de 21 de setembro de 2017. Política Nacional de Atenção Básica, no âmbito do Sistema Único de Saúde (SUS). Brasilia, DF: Presidência da República, 2017. Disponivel em: http://bvsms.saude.gov.br/bvs/saudelegis/gm/2017/ prt2436_22_09_2017.html. Acesso em: 14 dez. 2018.

BRASIL. Conselho Nacional sobre Drogas. Resolução $n^{\circ}$ 01/2018. Dispõe sobre o Realinhamento da Política sobre Drogas. Brasília, DF: Presidência da República, 2018. Disponivel em: http://www.justica.gov.br/news/politicas-sobre-drogas-dara-guinada-rumo-a-abstinencia/ proposta-aceita-osmar-terra.pdf. Acesso em: 29 jun. 2018.

BRASIL. Secretaria Nacional de Políticas sobre Drogas. Portaria no 8, de 27 de abril de 2018. Criação da Comissão Especial de Avaliação das Comunidades Terapêuticas. Brasilia, DF: Presidência da República, 2018. Disponivel em: https://Www.jusbrasil.com.br/ diarios/195205618/dou-secao-2-15-06-2018-pg-43. Acesso em: 29 jun. 2018.
BRASIL. Resolução CONAD nº 01/2015. Regulamenta, no âmbito do Sistema Nacional de Politicas sobre Drogas (SISNAD), as entidades que realizam o acolhimento de pessoas, em caráter voluntário, com problemas associados ao uso nocivo ou dependência de substância psicoativa, caracterizadas como comunidades terapêuticas. Brasilia, DF: Presidência da República. Disponivel em: http://Www.politicasobredrogas.pr.gov. br/arquivos/File/CONAD_01_2015.pdf. Acesso em: 25 set. 2018

BRASIL. Ministério da Justiça e Segurança PúblicaDepartamento Penitenciário Nacional. Levantamento Nacional de Informações Penitenciárias - Brasilia, DF: Presidência da República. 2019. Disponível em: https:// app.powerbi.com/view?r=eyjrijoimmu4odawntatyziym s00owjilwezztgtzgnjyzzhntyzzdliiiwidci6imvimdkwndiwltqongmtndnmny05mwyyltriogrhnmjmzthlmsjg. Acesso em: 12 jan. 2021

BURNS, John E.; LABONIA FILHO, Walter. Grupos de Ajuda Mútua no tratamento de pessoas dependentes de substâncias psicoativas. In: FORMIGONI, Maria L. O. S.; DUARTE, Paulina C. A. V (org.). O Sistema Único de Assistência Social e as Redes Comunitárias: módulo 7. 11. ed. Brasilia: Secretaria Nacional de Políticas sobre Drogas, 2017. p. 77-86. (SUPERA: Sistema para detecção do Uso abusivo e dependência de substâncias Psicoativas: encaminhamento, intervenção breve, reinserção social e acompanhamento).

CASTELO, Rodrigo. O novo-desenvolvimentismo e a decadência ideológica do estruturalismo latino-americano. In: CASTELO, Rodrigo (org.). Encruzilhadas da América Latina no século XXI. Rio de Janeiro: Pão e Rosas, 2010. p. 71-91.

CAMPOS, Gastão Wagner de Sousa; DOMITTI, Ana Clara. Apoio matricial e equipe de referência: uma metodologia para a gestão do trabalho interdisciplinar em saúde. Cad. Saúde Pública, [S. I.], v. 23, n. 2, p. 399-407, 2007.

COSTA, Nilson do Rosário. Politicas Públicas, Justiça Distributiva e Inovação: saúde e saneamento na agenda social. São Paulo: Hucitec, 1998.

COSTA, Pedro Henrique Antunes da; COLUGNATI, Fernando Antonio Basile; RONZANI, Telmo Mota. As redes de atenção aos usuários de álcool e outras drogas: histórico, politicas e pressupostos. In: RONZANI, Mota Telmo et al. (org.). Redes de atenção aos usuários de drogas: politicas e práticas. São Paulo: Cortez, 2015. p. 738-750

DUARTE, Paulina do Carmo Arruda Vieira. Recursos da comunidade para lidar com o uso abusivo e a dependência de álcool e outras drogas: alternativas e reinserção social. In: FORMIGONI, Maria L. O. S.; DUARTE, Paulina C. A. V (org.). O Sistema Único de Assistência Social e as Redes Comunitárias: módulo 7. 11. ed. Brasília: Secretaria Nacional de Políticas sobre Drogas, 2017. p. 59-76. (SUPERA: Sistema para detecção do Uso abusivo e dependência de substâncias Psicoativas: encaminhamento, intervenção breve, reinserção social e acompanhamento).

ELY, Karine Zenatti. CAPS AD III: cotidiano, avanços e desafios. In: TOROSSIAN, Sandra D. et al. (org.). Descriminalização do Cuidado: políticas, cenários e experiências em redução de danos. Porto Alegre, RS: Rede Multicêntrica, 2017. p. 351-364. 
GOMES, Tathiana Meyre da Silva. Reflexões sobre o processo de implementação da Política Nacional de Saúde Mental, Álcool e outras Drogas no Brasil neoliberal. In: DUARTE, Marco José de Oliveira et al. (org.). Serviço Social, Saúde Mental e Drogas. Campinas: Papel Social, 2017

KOSIK, Karel. Dialética do Concreto. 6. ed. São Paulo: Paz e Terra, 2002.

MARLATT, Gordon Alan. Redução de Danos: estratégias práticas para lidar com comportamentos de alto risco. Porto Alegre: Artes Médicas. 1999

MARTINELLI, M. Lúcia (org.). O uso de abordagens qualitativas na pesquisa em Serviço Social. Cadernos NEPI. São Paulo: PUCSP, 1994.

MELLO, Vania Roseli Correa de; PAULON, Simone Mainieri. Travessias de Humanização na Saúde Mental: tecendo redes, formando apoiadores. In: BRASIL. Ministério da Saúde. Secretaria de Atenção à Saúde. Departamento de Ações Programáticas Estratégicas. Saúde Mental/Ministério da Saúde, Secretaria de Atenção à Saúde, Departamento de Ações Programáticas Estratégicas. Cadernos Humaniza SUS. Brasilia: Ministério da Saúde, 2015. v. 5, p. 86-105.

MINOZZO, Fabiane et al. Saúde Mental, Atenção Primária à Saúde e Integralidade. In: FORMIGONI, Maria L. O. S.; DUARTE, Paulina C. A. V (org.). Atenção integral na rede de saúde: módulo 5. 11. ed. Brasília: Secretaria Nacional de Políticas sobre Drogas, 2017. p. 12-34. (SUPERA: Sistema para detecção do Uso abusivo e dependência de substâncias Psicoativas: encaminhamento, intervenção breve, reinserção social e acompanhamento).

MOTA, Ana Elizabete. Serviço Social e Seguridade Social: uma agenda recorrente e desafiante. Em Pauta: Teoria Social \& Realidade Contemporânea, Rio de Janeiro, n. 20, p. 127-138, 2007.

OBSERVATÓRIO BRASILEIRO DE INFORMAÇÕES SOBRE DROGAS. Ministério da Cidadania. Secretaria Nacional de Cuidados e Prevenção às Drogas. Brasília. Disponivel em: http://mds.gov.br/obid. Acesso em: 30 jan. 2019.

OLIVEIRA, Márcia Cristina de Oliveira. Direitos Humanos: uma nova cultura para a atuação em contextos de uso abusivo de drogas. In: FORMIGONI, Maria L. O. S.; DUARTE, Paulina C. A. V (org.). O Uso de Substâncias Psicoativas no Brasil: módulo 1. 11. ed. Brasília: Secretaria Nacional de Políticas sobre Drogas, 2017. p. 48-70.

ORGANIZAÇÃO MUNDIAL DA SAÚDE. Transtornos devido ao uso de substâncias. In: Organização Pan-Americana Da Saúde; Organização Mundial Da Saúde (org.). Relatório sobre a saúde no mundo. Saúde Mental: nova concepção, nova esperança. Brasilia: Gráfica Brasil, 2001. p. 58-61.

PEREIRA, Potyara Pereira. Como conjugar especificidade e intersetorialidade na concepção e implementação da política de assistência social. Serviço Social e Sociedade, São Paulo, Cortez, n. 77, p. 54-62, mar. 2004

PEREIRA, Potyara Pereira. Necessidades Humanas: subsídios à crítica dos mínimos sociais. 2. ed. São Paulo: Cortez, 2002.
PETUCO, D. R. S.; MEDEIROS, R. G. Saúde Mental, Álcool e outras Drogas. Contribuição à IV Conferência Nacional de Saúde Mental - Intersetorial. In: REDE Humaniza SUS, 4 abr. 2010. Disponivel em: http://redehumanizasus. net/9808-saude-mental-alcool-e-outras-drogas-contribuicao-a-iv-conferencia-nacional-de-saude-mental-intersetorial. Acesso em: 14 jun. 2018.

PRATES, Jane. O planejamento da pesquisa. Revista Temporalis, Porto Alegre, v. 7, n. 7, 2003.

RAICHELIS, Raquel. Proteção social e trabalho do assistente social: tendências e disputas na conjuntura de crise mundial. Serv. Soc. Soc., São Paulo, n. 116, p. 6og-635, out./dez. 2013

SILVA, Eroy Aparecida da. A participação da família na prevenção e no tratamento de dependência de álcool e outras drogsa: o papel dos pais e dos cônjuges. In: FORMIGONI, Maria L. O. S.: DUARTE, Paulina C. A. V (org.) O Sistema Único de Assistência Social e as Redes Comunitárias: módulo 7. 11. ed. Brasília: Secretaria Nacional de Politicas sobre Drogas, 2017. 148 p. (SUPERA: Sistema para detecção do Uso abusivo e dependência de substâncias Psicoativas: encaminhamento, intervenção breve, reinserção social e acompanhamento).

SECRETARIA DE PLANEJAMENTO, GOVERNANÇA E GESTÃO DO ESTADO DO RIO GRANDE DO SUL. Disponivel em: https://planejamento.rs.gov.br/inicial. Acesso em: 30 jan. 2019.

SUS/CNS. Sistema Único de Saúde. Conselho Nacional de Saúde. Comissão Organizadora da IV Conferência Nacional de Saúde Mental - Intersetorial. Relatório Final da IV Conferência Nacional de Saúde Mental Intersetorial, 27 de junho a 1 de julho de 2010. Brasilia: Conselho Nacional de Saúde/Ministério da Saúde. 2010. 210 p. Disponivel em: http://conselho.saude.gov. $\mathrm{br} /$ biblioteca/relatorios/relatorio_final_ivensmi_cns. pdf. Acesso em: 14 jun. 2018.

TEIXEIRA, Mirna Barros; RAMOA, Marise de Leão; ENGSTROM, Elyne; RIBEIRO, José Mendes. Tensões paradigmáticas nas políticas públicas sobre drogas: análise da legislação brasileira no periodo de 2000 a 2016. Ciência \& Saúde Coletiva, Rio de Janeiro, v. 22, n. 5, p. 1455-1466, 2017.

\section{Leonia Capaverde Bulla}

Doutora em Ciências Humanas - Educação pela Universidade Federal do Rio Grande do Sul (UFRGS), em Porto Alegre, RS, Brasil. Mestre em Serviço Social pela Université Laval, em Quebec, Canadá. Graduada em Serviço Social pela Universidade Federal de Santa Catarina (UFSC), em Florianópolis, SC, Brasil. Pós-doutora em Serviço Social pela Universidade de Kassel, em Kassel, Alemanha. Aposentada como professora Emérita do Curso de Serviço Social da Escola de Humanidades da Pontifícia Universidade Católica do RS (PUCRS), em Porto Alegre, RS, Brasil. Exerce atividades de ensino e pesquisa como professora colaboradora do Departamento de Serviço Social e/ou do Programa de Pós-graduação em Politica Social e Serviço Social do Instituto de Psicologia da Universidade Federal do Rio Grande do Sul (UFRGS), em Porto Alegre, RS, Brasil. 


\section{Camila Bassôa dos Santos}

Doutora em Serviço Social, Políticas e Processos Sociais pela Pontifícia Universidade Católica do Rio Grande do Sul (PUCRS), em Porto Alegre, RS, Brasil. Mestra em Serviço Social, Políticas e Processos Sociais pela Pontificia Universidade Católica do Rio Grande do Sul (PUCRS), em Porto Alegre, RS, Brasil.

\section{Endereço para correspondência}

Leonia Capaverde Bulla

Universidade Federal do Rio Grande do Sul

Rua Ramiro Barcelos, 2600, sala 401a

Santana, 90035-003

Porto Alegre, RS, Brasil

Os textos deste artigo foram revisados pela Poá Comunicação e submetidos para validação das autoras antes da publicação. 